\title{
Low Thermal Conductive Bi-2223 Tapes Sheathed with Ag-Au Alloys
}

\author{
Hiroyuki Fujishiro, Manabu Ikebe, Koshichi Noto and Michiaki Matsukawa \\ Department of Materials Science and Technology, \\ Faculty of Engineering, Iwate University, \\ Morioka 020, Japan \\ Takaaki Sasaoka, Katsumi Nomura, Jun-ichi Sato and Shoji Kuma \\ Advanced Research Center, Hitachi Cable, Ltd., \\ Tsuchiura 300, Japan
}

\begin{abstract}
With the view of applying to power current leads for superconductingmagnet systems and for other cryogenic power handling systems, low thermal conductive Bi-2223 superconducting tapes sheathed with Ag-Au alloy were fabricated and their thermal conductivities weremeasured from 12 to $260 \mathrm{~K}$. The critical current density (overall-J) was about $1700 \mathrm{~A} / \mathrm{cm}^{2}$ at $77 \mathrm{~K}, 0 \mathrm{~T}$ and remained nearly constant irrespective of Au concentration up to 11 at. $\%$. The tape sheathed with Ag+11at.\% Au alloy, of which the superconductor cross-section ratio $f_{s c}$ was 0.65 , had a thermal conductivity value about $0.2 \mathrm{~W} / \mathrm{cmK}$ at 77K. This value is as low as that of $\mathrm{Cu}-\mathrm{Zn}$. It was found that the thermal conductivity of the tape wasclose to the calculated one based on $f_{s} c$ and the independently measured thermal conductivities of the Ag-Au alloy and the Bi2223 superconductor. The superconducting tapes sheathed with the alloy were confirmed to be suitable for the application as power current leads.
\end{abstract}

\section{INTRODUCTION}

Since the discovery of high- $\mathrm{T}_{c}$ oxide superconductors, a great deal of research has been performed for their application to the cryogenic equipment such as high field superconducting magnets (SCM) and SCM energy storage (SMES) systems. For the power current lead use, both bulk oxide superconductors without metal stabilizer and oxide superconducting tapes sheathed with pure silver $(\mathrm{Ag})$ have been proposed in place of conventional copper leads [1]-[3]. Due to the small thermal conductivity of bulk oxide superconductors, heat intrusion through the leads can be kept low. Unfortunately, the relatively low critical current density (J) and fragility are disadvantages of the bulk superconductors which must be overcome. Oxide superconducting tapes sheathed with pure Ag have several advantages; the high-J characteristics due to the

Manuscript received September 20, 1993. increase of the crystal orientation in the core superconductor, the flexibility in use and an increase in thermal stability, etc. [4],[5]. The high thermal conductivity of the pure Ag sheath, however, causes a serious problem of the heat intrusion into the cryogenic apparatus. For power current leads, it is necessary to develop a new sheathing material to replace pure $\mathrm{Ag}$ which has a thermal conductivity as low as possible and which does not cause degradation of the superconducting characteristics such as $\mathrm{T}_{c}$ and $\mathrm{J}_{c}$.

A popular method of reducing the thermal conductivity of metals is alloying. As Ag is generally congenial to oxide superconductors, we fabricated the $\mathrm{Ag}-\mathrm{Au}$ and $\mathrm{Ag}-\mathrm{Cu}$ alloys as sheathing materials and investigated the dependence of the thermal conductivity and the electrical resistivity on the $\mathrm{Au}$ and $\mathrm{Cu}$ contents in the alloys [6]. It was found that the thermal and electrical conductivities of the Ag-Au alloy tapes, which were subjected to necessary heat treatment in oxidizing atmosphere to realize the superconducting tape, drastically decreased with increasing Au content up to 11at.\%. By contrast, the thermal and electrical conductivities of $\mathrm{Ag}-\mathrm{Cu}$ alloy tapes hardly decreased with an increase in Cu content because of the oxidation of $\mathrm{Cu}$ during the heat treatment. The superconduct ing characteristics of $\mathrm{Bi}_{2} \mathrm{Sr}_{2} \mathrm{CaCu}_{2} \mathrm{O}_{x}(\mathrm{Bi}-2212)$, thick films on these alloy substrates prepared by the doctor blade method [7] and $\mathrm{Bi}_{2} \mathrm{Sr}_{2} \mathrm{Ca}_{2} \mathrm{Cu}_{3} \mathrm{O}_{\mathrm{X}}$ (Bi-2223) superconducting tapes sheathed with the same alloys [8] were previously investigated. The $\mathrm{Ag}-\mathrm{Cu}$ alloys reacted with the $\mathrm{Bi}$-based isuperconductors and caused degradation of the superconducting characteristics. On the other hand, $\mathrm{Ag}-\mathrm{Au}$ alloys did not react with the Bi-based superconductors and are very promising materials for the metal stabilizer as a possible replacement for pure Ag.

In the following, we investigate the possibility of applying $\mathrm{Bi}-2223$ superconducting tapes sheathed with $\mathrm{Ag}-\mathrm{Au}$ alloys to the power current'leads. Firstly, we report the ther$\mathrm{mal}$ conductivities of the $\mathrm{Bi}-2223$ superconducting tapes sheathed with $\mathrm{Ag}-\mathrm{Au}$ alloys from 12 to $260 \mathrm{~K}$. The thermal conductivity is also calculated by use of the thermal conductivities of both the $\mathrm{Ag}-\mathrm{Au}$ alloy and the $\mathrm{Bi}-2223$ superconductor, and the superconductor cross-section ratio $f_{s c}$ which refers to the ratio of the core superconductor cross section to the total cross section of the tape. The calculated thermal conductivity is compared with the measured one and the estimation of the thermal conductivity is discussed for the current lead design. Secondly, the relation between the 
overall-J at $77 \mathrm{~K}, 0 \mathrm{~T}$ and the $\mathrm{Au}$ content in the $\mathrm{Ag}-\mathrm{Au}$ alloy sheath is investigated. Thirdly, the heat intrusion through a $100 \mathrm{~cm}$ current lead of $1000 \mathrm{~A}$ with a stacking structure made by assembling $\mathrm{Ag}-\mathrm{Au}$ sheathed tapes is theoretically determined using the characteristics of the tape. Lastly, the electrical resistivities of the $\mathrm{Ag}$-Au alloy tapes are measured under magnetic fields up to $12 \mathrm{~T}$ in order to estimate the effect of the magnetoresistance. The influence of magnetic field on the thermal conductivity of the core superconductor is also discussed.

\section{EXPERIMENTAL}

\section{A. Sample preparation}

$\mathrm{Ag}-\mathrm{Au}$ alloys containing $\mathrm{Au}$ from 0 to 30 at.\% were prepared using an RF induction furnace in a pure Ar atmosphere. $\mathrm{Ag}$ and $\mathrm{Au}$ of $4 \mathrm{~N}(99.99 \%)$ grade were used as raw materials. For the preparation of the superconducting tapes, the alloy was made into the tape-shape. $\mathrm{Bi}_{1.8} \mathrm{~Pb}_{0.4} \mathrm{Sr}_{2.0} \mathrm{Ca}_{2.2} \mathrm{Cu}_{3.0} \mathrm{O}$ (Bi-2223) oxide superconducting powder was fabricated as follows; $\mathrm{Bi}_{2} \mathrm{O}_{3}, \mathrm{PbO}, \mathrm{SrCO}_{3}, \mathrm{CaCO}_{3}$ and $\mathrm{CuO}$ raw powder of $4 \mathrm{~N}$ grade were mixed and calcined at $800^{\circ} \mathrm{C}$ for 20 hours. After pulverizing the calcined material, the resulting powder was wrapped with alloy tape and then cold-rolled into a tape. Finally, the tape was heat treated at the maximum temperature of $840^{\circ} \mathrm{C}$ in air which was necessary for Bi-2223 superconducting tape. The finished tape was about $300 \mu \mathrm{m}$ in thickness and about $8 \mathrm{~mm}$ in width. Sintered Bi-2223 superconducting polycrystal was also fabricated under the same heat treatment conditions using the calcined powder in order to evaluate the thermal conductivity of the core superconductor. Ag-Au alloy tapes without the superconducting core were also fabricated with about $50 \mu \mathrm{m}$ in thickness and about $2 \mathrm{~mm}$ in width to measure the thermal conductivity and electrical resistivity. The alloy tapes were heat treated under the same conditions as the superconducting tapes.

\section{B. Measurements}

The thermal conductivities of the sheathed $\mathrm{Bi}-2223$ superconducting tapes, the alloy tapes and the sintered $\mathrm{Bi}-2223$ polycrystal were measured using a steady state heat flow method from 12 to $260 \mathrm{~K}$ with an automated measuring system of our own design [9]. The system made use of a GiffordMcMahon (G-M) cycle helium refrigerator as a cryostat. One end of the sample was soldered to the cold head of the refrigerator and a small resistance heater was attached to the other end of the sample by GE7031 varnish. Au+0.07at.\%Fe - chromel thermocouples of $73 \mu \mathrm{m}$ in diameter were used differentially to measure the differences in temperature. The electrical resistivity was measured by a conventional fourprobe method in the same refrigerator from 12 to $300 \mathrm{~K}$, and in liquid helium at $4.2 \mathrm{~K}$. In order to investigate the influence of the heat treatment on the sheathing alloy, the electrical resistivity of as-rolled alloy tapes was also measured. To study the effect of the magnetoresistance, the electrical resistivities of the alloy tapes were measured at $4.2 \mathrm{~K}$ under a magnetic field up to 12 Tesla. The $f_{s c}$ was decided from observations of the tape cross section using an optical microscope.

\section{RESULTS and DISCUSSION}

\section{$A$. Thermal conductivity and electrical resistivity of $A g-A u$ alloys}

Fig. 1 shows the temperature dependence of the thermal conductivity of the heat treated $\mathrm{Ag}-\mathrm{Au}$ alloy tapes ( $\mathrm{K}_{\text {allor }}$ ) with various concentrations of $A u$ up to $30 a t . \%$. $k$ alloy drastically decreased with increasing Au content at low temperatures. The thermal conductivity of the tape with 11 at.\%Au was by about three orders smaller than that of the pure $\mathrm{Ag}$ tape at $20 \mathrm{~K}$. In the $\mathrm{Au}$ concentration range from 11 to 30 at.\%, the further decrease of the thermal conductivity became gradual. This may correspond to the saturation tendency associated with the Au content getting nearer to 50at.\%. Thus, the thermal conductivity of the Ag-Au alloy tape with Au content up to about 11at.\% is confirmed to decrease drastically with increase in Au content. The thermal conductivity data shown in Fig.1 are fairly consistent with those by Crisp et al [10].

Fig. 2 shows the temperature dependence of the electrical resistivity of the heat treated $\mathrm{Ag}-\mathrm{Au}$ alloy tapes. The electrical resistivity drastically increased with an increase in the Au content at low temperatures. For example, the electrical resistivity of the $\mathrm{Ag}+11 \mathrm{at} . \% \mathrm{Au}$ alloy tape was by about three orders larger than that of the pure $\mathrm{Ag}$ tape at $20 \mathrm{~K}$. As the electronic thermal conductivity and the electrical resistivity are related to one another by the Wiedemann-Franz law, the Au content dependences in Figs.1 and 2 are reasonable.

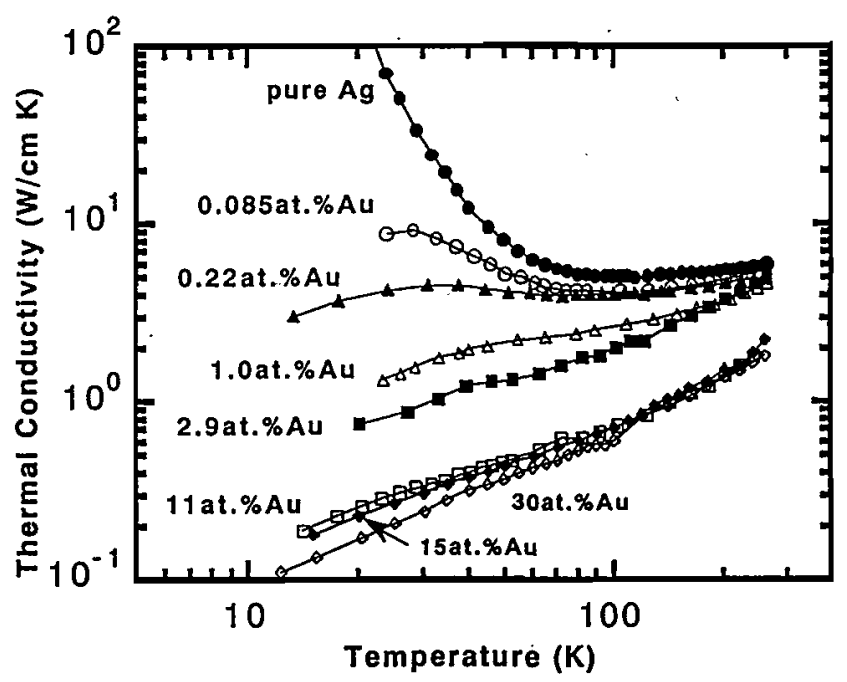

Fig. 1. Temperature dependence of the thermal conductivity of heat treated $\mathrm{Ag}-\mathrm{Au}$ alloy tapes with the various concentrations of Au. 


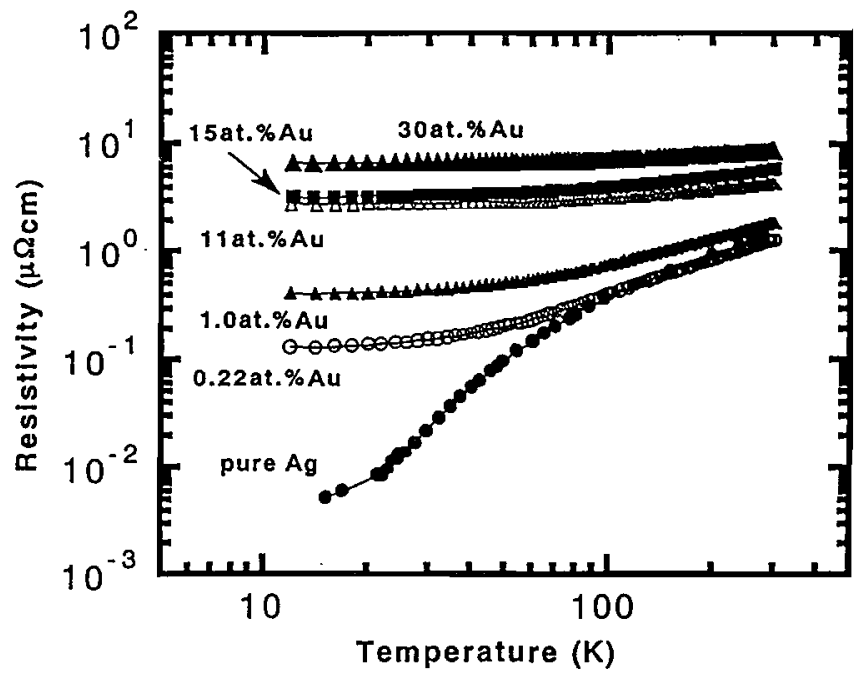

Fig. 2. Temperature dependence of the electrical resistivity of heat treated Ag-Au alloy tapes with the various concentrations of $\mathrm{Au}$.

To investigate the influence of heat treatment in air on the physical properties of the Ag-Au alloys, the electrical resistivity of the as-rolled alloy tapes was also measured. Fig. 3 shows the temperature dependence of the electrical resistivities of both the as-rolled tapes (AR) and the heat treated tapes (HT) witl Au content from 0.22 to 11 at.\%. It was found that the heat treatment results in a slight decrease of the resistivity values at low temperatures and also a slight increase of the temperature dependence of the resistivity. The decrease of the resistivity at low temperatures may come from the decrease of the dislocation density and the increase of the temperature dependence may come from the softening of the alloy caused by the heat treatment. However, both effects are rather small and, according to the Wiedeman-Franz law, also the thermal conductivity of the alloys should not be much influenced by the heat treatment in air.

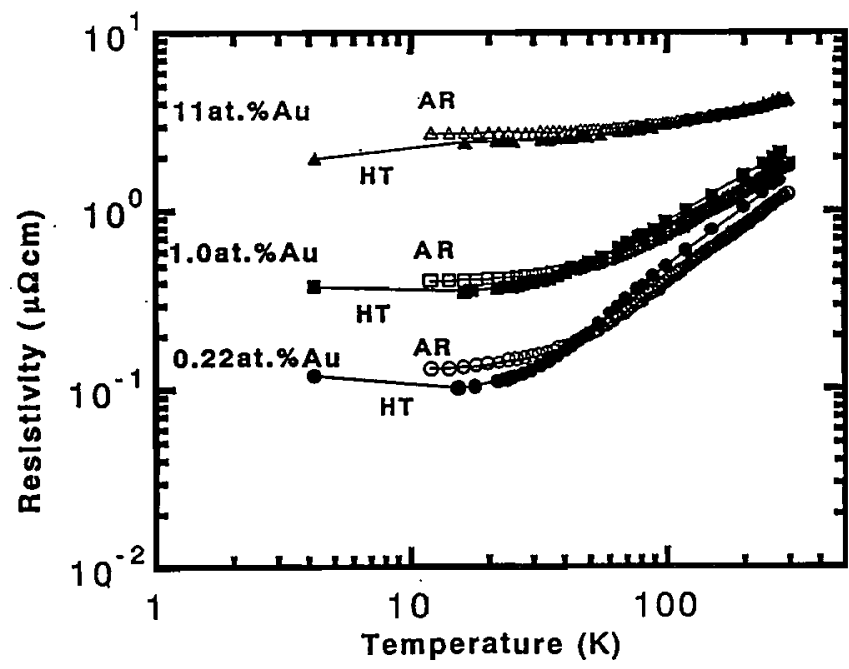

Fig. 3. Temperature dependence of the electrical resistivities of both the as-rolled $\mathrm{Ag}-\mathrm{Au}$ tapes (AR) and the heat treated tapes (HT) in which Au contains from 0.22 to 11 at.\%.
$B$ Thermal conductivity of the Bi-2223 superconducting tapes

The thermal conductivities of the $\mathrm{Bi}-2223$ superconducting tapes with various Aucontents and superconductor cross-section ratios $\mathrm{f}_{\mathrm{sc}}$ were investigated. The superconducting transition temperatures of these tapes were about $104 \mathrm{~K}$ and independent of the Au content and $\mathrm{f}_{\mathrm{sc}}$. Figs. 4 and 5 show the temperature dependence of the thermal conductivity of the $\mathrm{Bi}-2223$ superconducting tapes $\left(\boldsymbol{\kappa}_{\mathrm{AgAuT}}\right)$ sheathed with $\mathrm{Ag}+11$ at. \% Au alloy $\left(\mathrm{f}_{\mathrm{sc}}=0.65\right)$ (hereinafter referred to as No.1 sample), and sheathed with $\mathrm{Ag}+15$ at.\%Au alloy $\left(f_{s c}=0.33\right.$ ) (hereinafter as No.2 sample) with closed circles, respectively. In these figures, the thermal conductivities of the $\mathrm{Ag}-\mathrm{Au}$ alloy tapes with the same Au content $\left(\kappa_{\text {alloy }}\right.$ in Fig.1) and the Bi-2223 sintered polycrystal ( $\left.\kappa_{\text {poly }}\right)$ are also shown with open circles and closed triangles, respectively. $\mathrm{K}_{\text {poly }}$ was $24 \mathrm{~mW} / \mathrm{cmK}$ at $200 \mathrm{~K}$ and decreased monotonically with decreasing temperature. $\mathrm{K}_{\text {poly }}$ showed a significant upturn just below $\mathrm{T}_{c}(=105 \mathrm{~K})$ and took a local maximum around $70 \mathrm{~K}$, and then decreased steeply with further lowering temperatures. The value of $k_{\text {poly }}$ is about two orders smaller than that of $\mathrm{Ag}-\mathrm{Au}$ alloy tape with 11 and 15 at.\% Au content. It is found that the magnitude of $K$ lies between those of $\kappa_{\text {alloy }}$ and $\kappa_{\text {poly }}$.

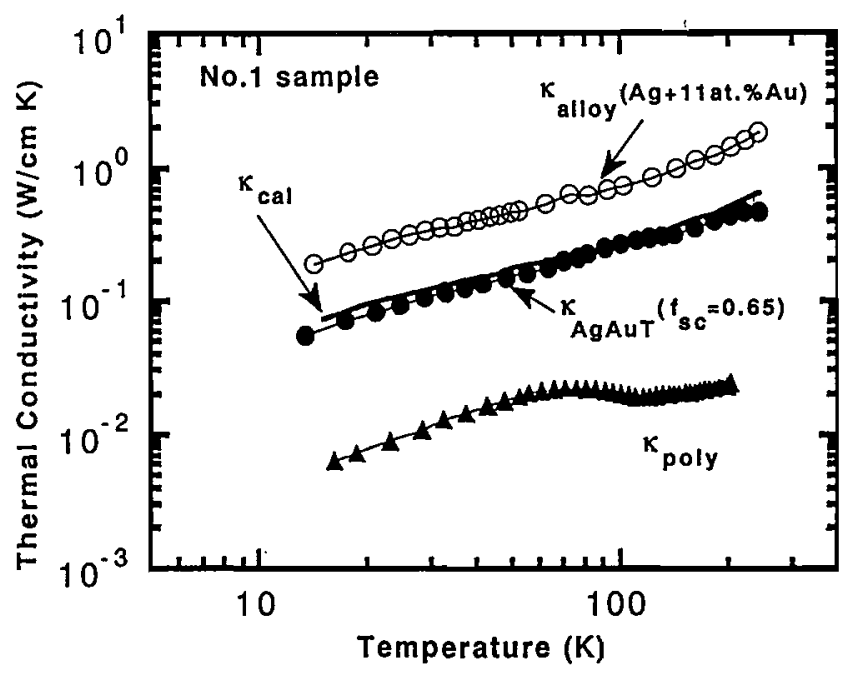

Fig. 4. Temperature dependence of the thermal conductivity $\kappa_{\text {AgAuT }}$ of Bi-2223 superconducting tape (No.1 sample) sheathed with $\mathrm{Ag}+11$ at. \% Au alloy for ratio $\mathrm{f}_{\text {sc }} 0.65$ (closed circles). The thermal conductivity of $\mathrm{Ag}+11 \mathrm{at} . \% \mathrm{Au}$ alloy tape $\mathrm{\kappa}_{\text {alloy }}$ (open circles) and that of $\mathrm{Bi}-2223$ polycrystal $\kappa_{\text {poly }}$ (closed triangles) and the calculated thermal conductivity $\kappa_{\text {cal }}$ (thick line) were also shown. 


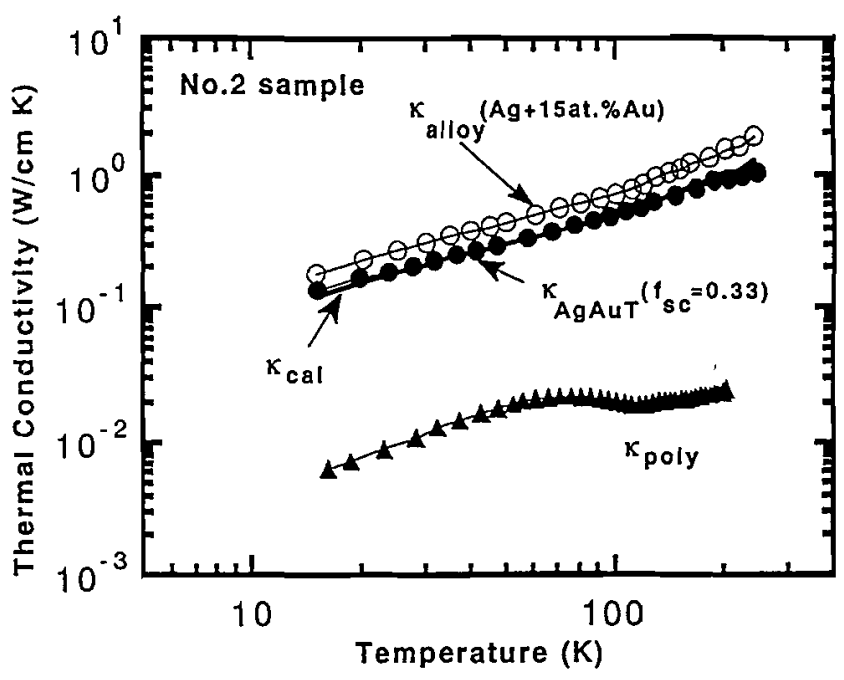

Fig. 5. Temperature dependence of the thermal conductivity of Bi-2223 superconducting tape (No.2 sample) sheathed with Ag+15at.\%Au alloy for core ratio $f_{s c} 0.33$ (closed circles). The thermal conductivity of $\mathrm{Ag}+15 \mathrm{at} . \% \mathrm{Au}$ alloy tape (open circles), that of $\mathrm{Bi}-2223$ polycrystal (closed triangles) and the calculated thermal conductivity (thick line) are also shown.

As the superconducting tape consists of the $\mathrm{Bi}-2223$ superconducting core and the $\mathrm{Ag}$ - $\mathrm{Au}$ alloy sheath, the heat should flow in parallel through both the core and the sheath along the tape. In this case, the thermal conductivity $\kappa_{\text {cal }}$ of the superconducting tape can be calculated using the values of $K_{\text {poly }}, K_{\text {alloy }}$ and $f_{s c^{\prime}}$, by

$$
\mathrm{K}_{\text {cal }}=\mathrm{f}_{\mathrm{sc}} \mathrm{K}_{\text {poly }}+\left(1-\mathrm{f}_{\mathrm{sc}}\right) \mathrm{K}_{\text {alloy }}
$$

$\mathrm{K}_{\mathrm{cal}}$ was also shown in Figs. 4 and 5 with thick solid lines. The calculated $\mathrm{K}_{\text {cal }}$ is very close to the experimentally obtained thermal conductivity $k{ }_{A g A u}$. This confirms that the thermal conductivity of a superconducting tape with arbitrary superconductor cross-section ratio $\mathrm{f}_{\mathrm{sc}}$ and with some Au concentration in the Ag-Au alloy sheath can be practically estimated by use of Eq.(1). It is useful in power current lead design to be able to estimate the heat flow through the lead rather than to measure it. For comparison, the thermal conductivities of $\mathrm{Bi}-2223$ tapes $\left(f_{\mathrm{sc}}=0.23\right)$ sheathed with a pure $\mathrm{Ag}$ sheath $\left(\mathrm{K}_{\mathrm{AgT}}\right)$, and the high purity copper $(4 \mathrm{~N})\left(\mathrm{K}_{\mathrm{Cu}}\right)$ used in conventional power current leads were also measured. Fig. 6 shows the temperature dependence of $\mathrm{K}_{\mathrm{Ag} T}$ and $\mathrm{K}_{\mathrm{Cu}}$, together with the thermal conductivities of samples No.1 and 2 , the heat treated pure $\mathrm{Ag}(4 \mathrm{~N})$ tape, a $\mathrm{Cu}-\mathrm{Zn}$ alloy and $\mathrm{K}_{\text {poly }} \cdot \mathrm{K}_{\mathrm{AgT}}$ is only slightly smaller than the thermal conductivity of the pure $\mathrm{Ag}$ tape because of the low $\mathrm{f}_{\mathrm{sc}} \mathrm{K}_{\mathrm{Cu}}$ is almost the same as $\mathrm{K}_{\mathrm{AgT}}$ from 40 to $200 \mathrm{~K}$. The thermal

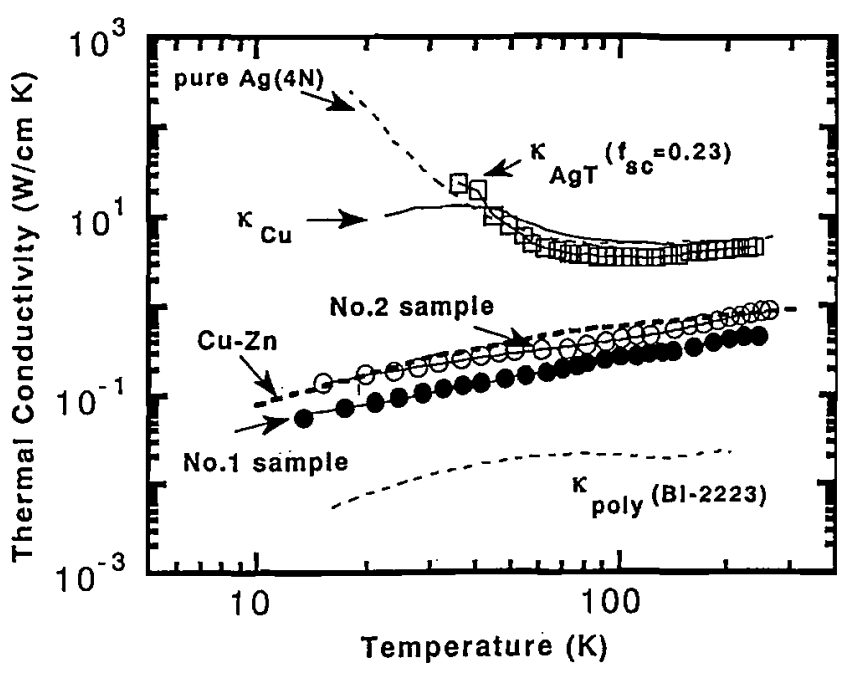

Fig. 6. Temperature dependence of thermal conductivities of both the $\mathrm{Bi}-2223$ superconducting tapes sheathed with pure $\mathrm{Ag}\left(f_{s c}=0.23\right)$ and the high purity copper of $4 \mathrm{~N}$ grade.

For comparison, the thermal conductivities of the pure $\dot{A g}(4 \mathrm{~N})$ tape, No.1 and 2 samples, a $\mathrm{Cu}-\mathrm{Zn}$ alloy and $\mathrm{Bi}-$ 2223 polycrystal are also shown.

conductivity of No.1 and 2 samples is about $0.2 \mathrm{~W} / \mathrm{cmK}$ at $77 \mathrm{~K}$ which is comparable to that of the $\mathrm{Cu}-\mathrm{Zn}$ alloy.

\section{Characteristics of overall-J}

The overall-J ${ }_{c}$ characteristics of the $\mathrm{Bi}-2223$ tape sheathed with $\mathrm{Ag}-\mathrm{Au}$ alloy for various Au contents were measured [8] Overall- $J_{c}$ of the tape is defined by

$$
\text { overall- } J_{c}=\frac{\mathrm{I}_{\mathrm{c}}}{\mathrm{S}}
$$

where $I_{c}$ is the critical current and $S$ is the total cross section of the tape. Fig. 7 shows the relation between the Au content in the $\mathrm{Ag}-\mathrm{Au}$ alloy sheath and the overall- $J_{c}$ of the tape, in which $\mathrm{f}_{\mathrm{sc}}$ is kept to 0.65 , at $77 \mathrm{~K}$ and $0 \mathrm{~T}$. The overall- $\mathrm{s}_{c^{\prime}}$ remained almost constant at about $1700 \mathrm{~A} / \mathrm{cm}^{2}$, irrespective of Au contents in the Ag-Au alloy sheath up to 11 at.\%. As the $\mathrm{J}_{\mathrm{c}}$ of $\mathrm{Bi}-2223$ sintered polycrystal was about $500 \mathrm{~A} / \mathrm{cm}^{2}$ at $77 \mathrm{~K}$ and $0 \mathrm{~T}[11]$, it was found that the overall-J of the Bi2223 superconducting tape was about three times larger than that of the Bi-2223 sintered sample. Fig. 8 shows the magnetic field dependence of the overall-J ${ }_{c}$ of the Bi-2223 tape $\left(f_{s c}=0.65\right)$ sheathed with $\mathrm{Ag}-\mathrm{Au}$ alloy with various $\mathrm{Au}$ contents at $77 \mathrm{~K}$. The magnetic fields were applied parallel to the tape surface. The overall-J vs. magnetic field curves of the tapes sheathed with $\mathrm{Ag}$-Au alloys agreed with that of the 


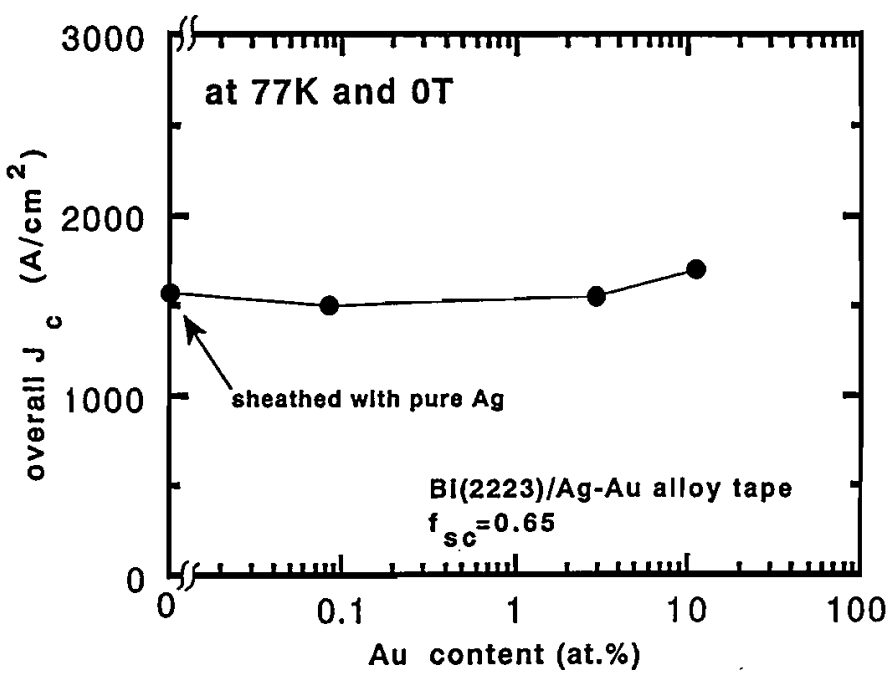

Fig. 7. Overall-J of the Bi-2223 superconducting tapes with various concentrations of $A u$ at $77 \mathrm{~K}$ and $0 \mathrm{~T}$, in which the superconducting core ratio $\mathrm{f}_{\mathrm{sc}}$ is 0.65 .

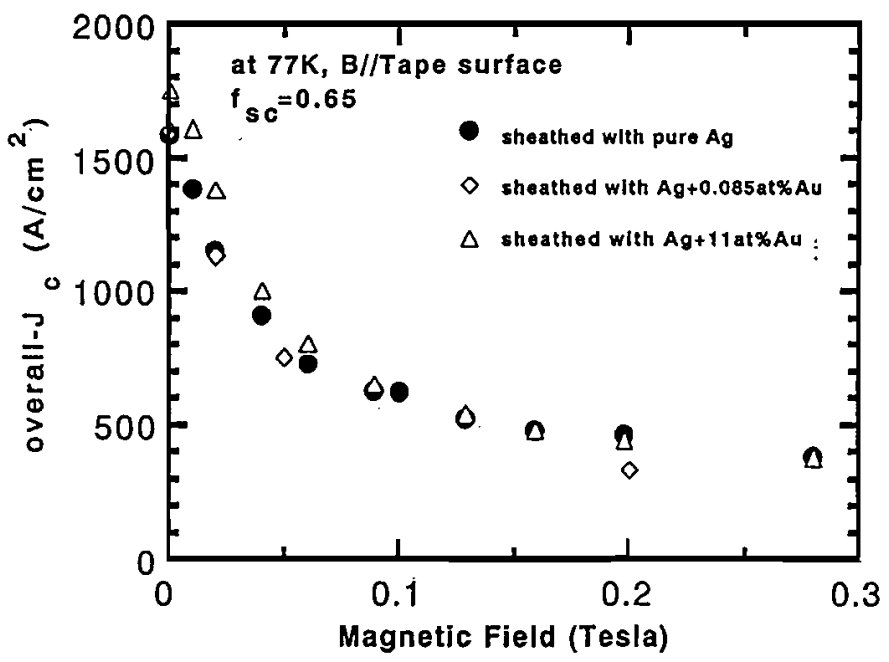

Fig. 8. Overall-J $J_{c}$ vs. applied magnetic field curves with various $\mathrm{Au}$ contents in the Ag-Au alloy sheathes at $77 \mathrm{~K}$. The magnetic field was applied parallel to the tape surface.

pure-Ag sheathed tape. It is recognized that the overall-J can be somewhat increased by decreasing $f_{s c}$ below 0.65 because of the resultant higher crystal orientation of the superconducting core. However, the heat intrusion through the tape increases at the same time because of the lower $f_{s c}$. It is necessary to optimize the Au content in the alloy sheath and the $f_{s c}$, according to the purpose of each cryogenic apparatus.

\section{Calculation of heat intrusion through the current lead}

As the thermal conductivity of the superconducting tapes can be estimated using Eq.(1) as shown in Figs. 4 and 5, the heat intrusion through the current lead using the superconducting tapes was calculated. The heat intrusion $Q$ of the current lead in the area between $77 \mathrm{~K}$ and $4.2 \mathrm{~K}$ is given by

$$
Q=\frac{S}{L} \int_{4.2}^{77} \kappa_{c a l} d \Gamma
$$

where $L$ is the length and $S$ is the cross section of the lead, respectively. We used the $\mathrm{Bi}-2223$ superconducting tapes sheathed with $\mathrm{Ag}$ - $\mathrm{Au}$ alloy with $\mathrm{f}_{\mathrm{sc}}=0.65$ as shown in Fig.7, and calculated the $Q$ value for a $100 \mathrm{~cm}$ current lead of $1000 \mathrm{~A}$ .using Eqs. from (1) to (3).

Fig. 9 shows the results of the calculation of the relation between the heat intrusion through the lead and the $\mathrm{Au}$ content in the $\mathrm{Ag}-\mathrm{Au}$ alloy sheath. The heat intrusion $\mathrm{Q}$ of the current lead decreases with increased Au content. For example, the $Q$ value of a superconducting lead sheathed with the $\mathrm{Ag}+11 \mathrm{at} . \% \mathrm{Au}$ alloy is about two orders smaller than that of a conventional copper lead without gas cooling or a $\mathrm{Bi}$ 2223 superconducting lead sheathed with pure Ag.

\section{E. Influence of magnetic field}

In many cases power current leads for cryogenic equipment such as SCMs are used under magnetic fields. The influence of magnetic fields on the electrical resistivity of $\mathrm{Ag}-\mathrm{Au}$ alloy tapes was investigated. Fig. 10 shows the electrical resistivities of the $\mathrm{Ag}-\mathrm{Au}$ alloy tapes as a function of magnetic fields up to $12 \mathrm{~T}$. The electrical resistivity of tapes with higher Au content depends hardly at all on the magnetic field. This independence is a favorable condition for stable operation of superconducting power current leads with alloy sheathes. Although the intrinsic thermal stability of superconducting tapes sheathed with alloys somewhat deteriorates due to large electrical resistivity in the sheath, the electrical resistivity of bulk oxide superconductors in the normal state is several $\mathrm{m} \Omega \cdot \mathrm{cm}$, which is three orders larger than that of the Ag-Au alloy tapes. It should still be

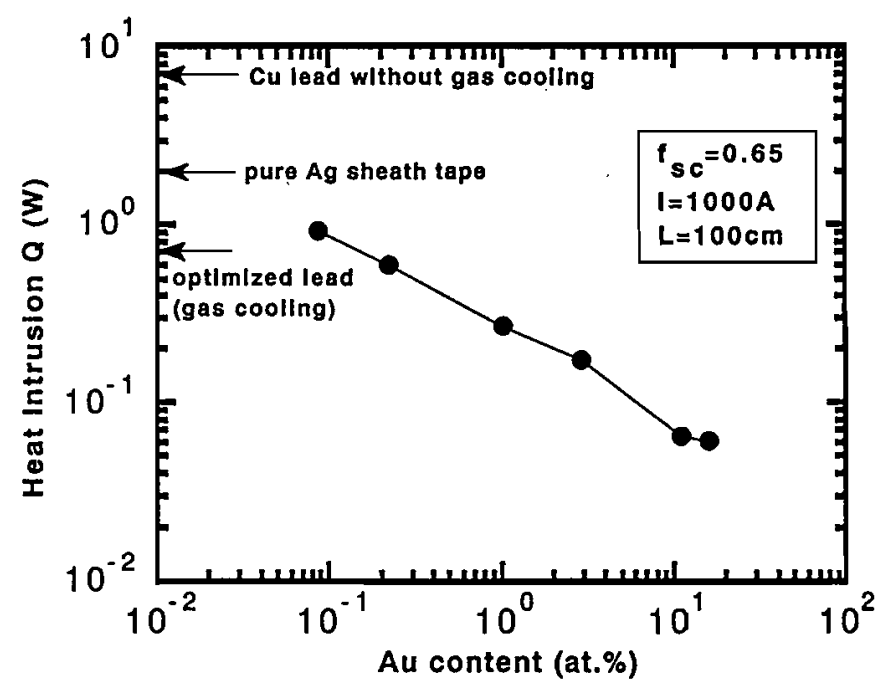

Fig.9. Relation between the heat intrusion through a $100 \mathrm{~cm}$ superconducting lead of $1000 \mathrm{~A}$ which is $\mathrm{f}_{\mathrm{sc}}=0.65$ and the Au content in the Ag-Au alloy sheath. 


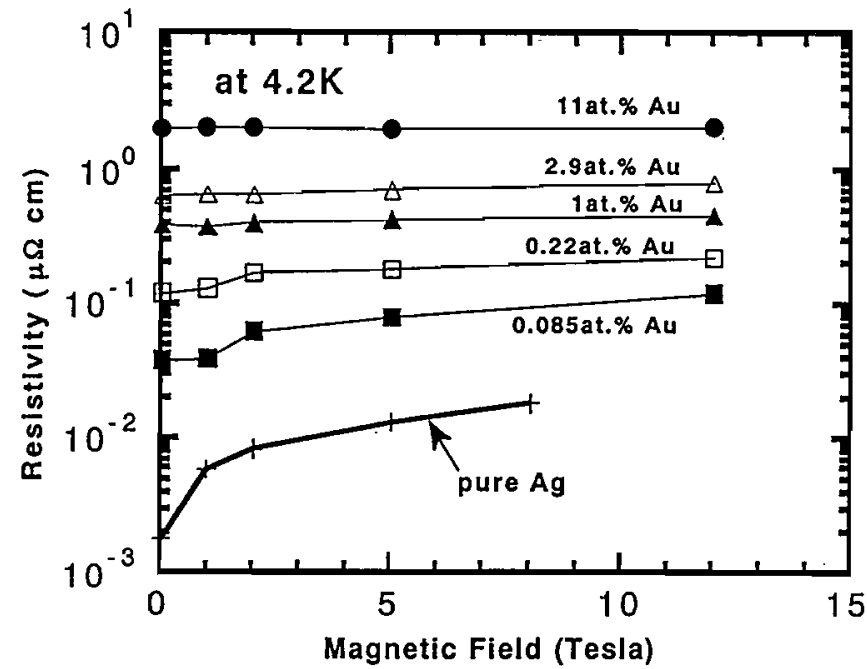

Fig. 10. Magnetic field dependence of the electrical resistivity of $\mathrm{Ag}-\mathrm{Au}$ alloys with various concentrations of $\mathrm{Au}$ at $4.2 \mathrm{~K}$.

beneficial for the thermal stability of superconducting power lệads to use the Ag-Au alloy sheath. The thermal conductivity of the oxide superconductor is sensitive to the magnetic field and decreases with increasing applied field below $T_{c}[12]$, and so could cause unstable operation of superconducting power current leads. Because the absolute value of the thermal conductivity of the Bi-2223 superconducting core is about one fiftieth smaller than that of $\mathrm{Ag}-\mathrm{Au}$ alloy as shown in this investigation, the thermal conductivity of the $\mathrm{Bi}-2223$ superconducting tape is expected to be nearly independent of the applied magnetic field.

\section{SUMMARY}

Low thermal conductive $\mathrm{Bi}-2223$ superconducting tapes sheathed with $\mathrm{Ag}-\mathrm{Au}$ alloys were developed for application to power current leads of cryogenic equipment. The tapes sheathed with the alloy with Au concentration up to 11 at.\% showed almost the same superconducting characteristics as those sheathed with pure Ag. Overall-J of about 1700 $\mathrm{A} / \mathrm{cm}^{2}$ at $77 \mathrm{~K}$ and $0 \mathrm{~T}$ was obtained, independent of the $\mathrm{Au}$ content in the Ag-Au alloy sheath. The thermal conductivity of $\mathrm{Bi}-2223$ tape sheathed with $\mathrm{Ag}+11$ at. \%Au alloy whose superconductor cross-section ratio $\mathrm{f}_{\text {sc }}$ was 0.65 was about $0.2 \mathrm{~W} / \mathrm{cmK}$ at $77 \mathrm{~K}$. This value is almost as low as that of $\mathrm{Cu}-\mathrm{Zn}$ alloy. The value of measured thermal conductivity can be reproduced by calculation based on the core ratio and the thermal conductivity values of both the $\mathrm{Ag}-\mathrm{Au}$ alloy and the superconducting core. The $\mathrm{Ag}-\mathrm{Au}$ alloy sheathed superconducting tapes give full promise for application in power current leads.

\section{ACKNOWLEDGEMENTS}

The authors wish to thank T.Kurihara and T.Naito of Iwate University for their assistance in the thermal conductivity and electrical resistivity measurements.

\section{REFERENCES}

[1] D.U.Gubser, M.M.Miller, N.McN.Alford and T.W.Buttom, "High-Capacity Superconducting Current Leads of $\mathrm{Y}_{1} \mathrm{Ba}_{2} \mathrm{Cu}_{3}$ $\mathrm{O}_{7-\mathrm{x}}$ ", Journal of Superconductivity, vol. 3, 1990, pp. 222-226

[2] K.Ueda et.al., "Design and Testing of a pair of Current Leads Using Bismuth Compound Superconductor", IEEE Trans. Appl. Supercond., vol. 3 , 1993 , pp.400-403

[3]P.F.Herrmann et al., "European Project for the Development of High $\mathrm{T}_{\mathrm{c}}$ Current Leads" IEEE Trans. Appl. Supercond. , vol. 3, 1993 , pp.876-880

[4]K.Sato et al., "Transport current properties of silver-sheathed BiPbSrCaCuO wire and coil", Cryogenics, vol. 31, 1991, pp.687-689

[5] J.R.Hull, A.Unal and M.C.Chyu, "Analysis of self-cooled binary current leads containing high temperature superconductors" Cryogenics, vol. 32, 1992, pp.822-828

[6] H. Fujishiro, M. Ikebe, K. Noto, T.Sasaoka and K. Nomura, "Thermal and Electrical Properties of $\mathrm{Ag}-\mathrm{Au}$ and $\mathrm{Ag}-\mathrm{Cu}$ Alloy Tapes for the Metal Stabilizer of Oxide Superconductors", Cryogenics, in press.

[7] K. Nomura et al., "Influence of Ag-Au and Ag-Cu alloys on $\mathrm{Bi}_{2} \mathrm{Sr}_{2} \mathrm{CaCu}_{2} \mathrm{O}_{\mathrm{X}}$ superconductor", Appl. Phys. Lett., in press.

[8] T.Sasaoka et al., "Characteristics of Bi-Pb-Sr-Ca-Cu-O/Ag -Au alloy sheathed superconducting tapes for current leads", unpublished.

[9] H.Fujishiro, T.Naito, M.Ikebe and K.Noto, "Low Temperature Thermal Diffusivity and Conductivity Measurements under an Identical Experimental Setup", Cryo. Eng. (in Japanese), vol.28, 1993, pp.533-539

[10] R.S.Crisp and J.Ruhgis, "Thermoelectric Power and Thermal Conductivity in the Silver-Gold Alloy System from 3-300K", Phil. Mag., vol. 22, 1970, pp.217-236

[11] J.L.Wuet al., "Design and testing of a high temperature superconducting current lead", IEEE Trans. Mag. , vol. 27, 1991, pp.1861-1865

[12] S.D.Peacor, J.L.Cohn and C.Uher, "Effect of magnetic field on thermal conductivity of $\mathrm{YBa}_{2} \mathrm{Cu}_{3} \mathrm{O}_{7 \cdot \mathrm{X}}$ single crystal", Phys. Rev.B , vol. 43, 1991, pp.8721-8724 